www.jmscr.igmpublication.org

Index Copernicus Value: 79.54

ISSN (e)-2347-176x ISSN (p) 2455-0450

crossref DOI: https://dx.doi.org/10.18535/jmscr/v7i3.244

\title{
Management of Deep bite: Review
}

\section{Authors \\ Dr Irum Uzma1, Prof. (Dr) Mohd. Tariq ${ }^{2}$, Dr Saba Khan ${ }^{3}$, Dr Grateful ${ }^{4}$}

\begin{abstract}
Deep bite is a frequently encountered malocclusion in children as well as in adults and is challenging to treat with significant success rate. Adverse sequel of this malocclusion predisposes a patient to periodontal problems, functional impairment, and temporomandibular joint disturbance. This article will elaborate various appliances, their indication and contraindication along with the various biomechanics involved.

Keywords: Deep overbite, Deep bite, orthodontic management.
\end{abstract}

\section{Introduction}

Deep bite is one of the most commonly occurring malocclusion seen next to crowding ${ }^{(1)}$ and its management is considered to be quite challenging to the clinician. It is classically defined as the increased vertical overlap of the upper anterior teeth onto the labial surface of lower anteriors in centric occlusion.1-2 mm of vertical overlap is considered to be normal ${ }^{(2)(3)}$. The crown length of the upper and lower incisors however may vary significantly in individuals. Therefore describing overbite in terms of "percentage" would be more descriptive, appropriate and useful. Upadhyay \& $\mathrm{Nanda}^{(4)} \mathrm{had}$ defined overbite as -the amount and percentage of overlap of the lower incisors by the upper incisors. An ideal overbite ranges from 5-25\% overlap.

\subsection{Etiology of Deepbite}

Skeletal or dental overbite may be caused by genetic or environmental factors (aquired) or a combination of both.

\subsubsection{Skeletal deep bites are characterized by}

1) Horizontal pattern of growth

2) Growth discrepancy of the jawbones
3) Convergent jaw bases, and/or

4) Decreased ramal height. ${ }^{(5)}$

5) In patients with deep bite, anterior facial height is often short, particularly the lower third of the face.

\subsubsection{Dental deep bites is characterized by}

1) Supraeruption of the anteriors ${ }^{(2) .(6)(7)}$

2) Excessive over jet ${ }^{(8)}$

3) Infra occlusion of the posterior teeth ${ }^{(2)(6)(5)(9)}$

4) Or a combination.

5) Alterations in the morphology of tooth. ${ }^{(10)(5)}$

6) Early loss of teeth may result in lingual tipping of the anterior teeth.

7) Failure of age-related opening of the bite. (12)(13)

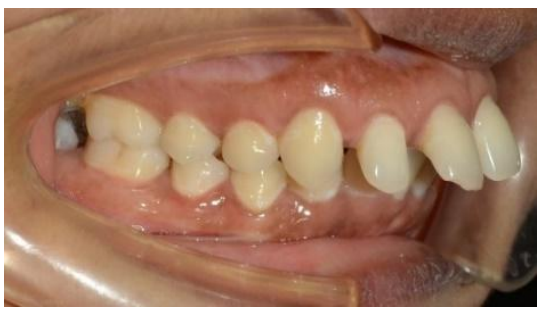

Fig.1- Supraerupted Anteriors 


\subsubsection{Acquired causes of dental deepbite}

1. A lateral tongue thrust resulting in infra occlusion of the posterior teeth.

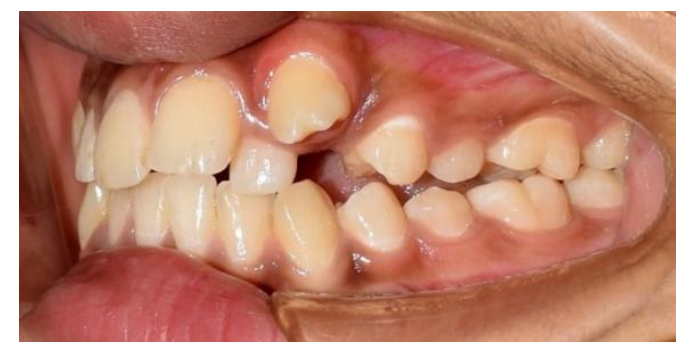

Fig.2- Lateral Tongue Thrust

2. Attrition and abrasion of teeth.

3. Anterior tipping of the posterior teeth into extraction sites.

4. Prolonged thumb sucking

In order to achieve optimal skeletal, dental and esthetic results, etiology of deepbite must be taken into consideration so as to formulate a comprehensive diagnosis and treatment plan for each patient.

\section{Diagnosis and Treatment planning}

A deep overbite can be corrected by extrusion of posterior teeth or by inhibition and genuine intrusion of anterior teeth, or by a combination.

\subsection{The choice of treatment is based on-}

1) Etiology of deep bite.

2) Amount of remaining growth.

3) The vertical dimension.

4) Relationship of the teeth with the adjoining soft tissue structures.

\subsection{Growth Consideration}

It is a well-known fact that correction of deep bite is easy and more stable when performed in growing patients rather when attempted in non-growing individuals. ${ }^{(14)(15)}$ As growth occurs, it tends to increase the vertical distance between maxilla and mandible, tooth eruption can be stimulated in posterior segments and inhibited in anterior segments because growth condylar region creates room for the dentoalveolar growth. In adults, any efforts to erupt molars is neutralised by the posterior occlusion, especially in horizontal growers. Even if attempted there is an upturn chances of relapse because it leads to alterations in muscle physiology thus fixed or removable appliances are needed to achieve optimal treatment results. Some adult patients might even require a surgical procedure.

\subsection{Consideration to Vertical Dimensions}

Vertical facial height needs to be taken into considered while managing deep bite patients as the extrusive or intrusive mechanics influence the anteroposterior relationship of the maxilla and mandible. In general, extrusion of posterior teeth should not infringe into the interocclusal space $^{(16)}$.The average interocclusal space is 2 to 4 $\mathrm{mm}$. In cases of increased freeway space posterior eruption is favourable.

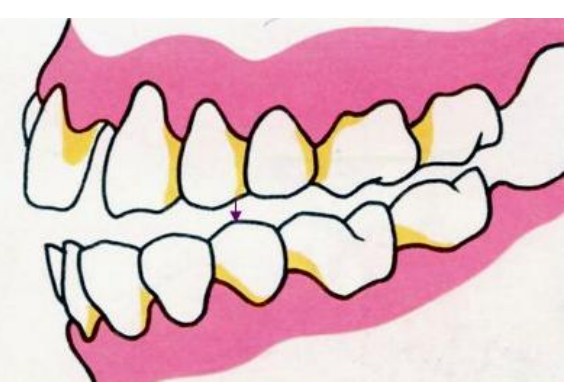

Fig.3- Freeway Space

\subsection{Soft Tissue Consideration}

Position of maxillary incisor relative to the upper lip should be taken into consideration IN decision making whether to maintain or intrude the upper incisors. Amount of incisal exposure should be evaluated in three different situation i.e. at rest position, during smiling and at speech. In a relaxed posture, 2 to $4 \mathrm{~mm}$ of incisor exposure is acceptable. In males most "pleasing" smiles is when there is no gingival exposure whereas in females 1 to $2 \mathrm{~mm}$ of exposure is considered to be normal. Increased gingival show may require selective intrusion of the upper incisors. If the relation of upper incisor to lower lip is normal the treatment plan should than focus either on posterior extrusion (if the vertical parameters permit) or intrusion of lower incisors

Incisor exposure during speech may also give additional information because different facial muscles are involved. Another important factor to consider is the interlabial gap. In patients exhibiting large interlabial gap, incisor intrusion is indicated. 
In individuals with no interlabial gap but they display excessive overbite, posterior extrusive mechanics may be considered. Proclining the lower incisors is another option however, it may be useful in individual presenting with retroclined incisors. (17)

\section{Treatment Modalities of Deep Bite}

Methods of deep bite correction:

1) Extrusion of Posterior Teeth.

2) Intrusion of Anterior Teeth.

3) Combination of Both.

4) Proclination of Incisors.

5) Surgical.

\subsection{Extrusion of Posterior Teeth}

Deepbite correction by extrusion of posterior is usually indicated in horizontal growing patients with normal interlabial gap and upper incisor to lip relation.

\subsubsection{Bite Plates}

Currently, bite planes are the most popular appliances for deep bite correction They load the incisors for an intrusive effect but leave the posterior teet to erupt, thereby leveling the curve of Spee primarily by posterior extrusion ${ }^{(4)}$. Sleichter found that alveolar height in the molar region increased. Anterior bite can be modified into sved bite planes ${ }^{(18)(19)}$ or they may be fixed bite with glass ionomer cement ${ }^{(20)}$ bonded bite planes with composite resin (indirect technique) on the palatal aspect of maxillary incisors also can be used for extrusion. ${ }^{(21)}$ Bite plates can also be incorporated in Nance appliance.

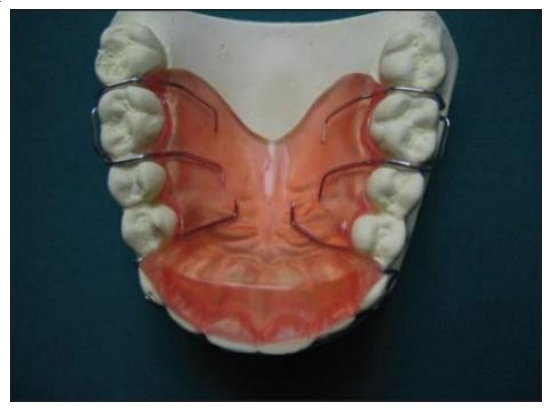

Fig.4 Anterior Bite Plate

\subsubsection{Functional Appliances}

Functional appliances whether removable or fixed can be used to achieve posterior extrusion to correct deep bites especially in low-angle Class II cases. Functional appliances help in positioning the lower jaw forward thereby disoccluding the posterior teeth, which are free to erupt. Myofunctional

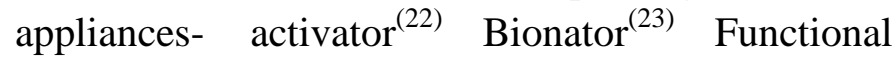
regulator $^{(24)}$ Twin blocks ${ }^{(25)}$ allows the extrusion of posterior teeth thus opening the bite. For treatment to succeed, however, the removable appliance must be worn almost full-time. Unfortunately, a significant number of patients do not fully comply, and appliances are often worn only part-time or may be lost or broken while out of the mouth. Many of these problems can be overcome by using fixed functional appliances.
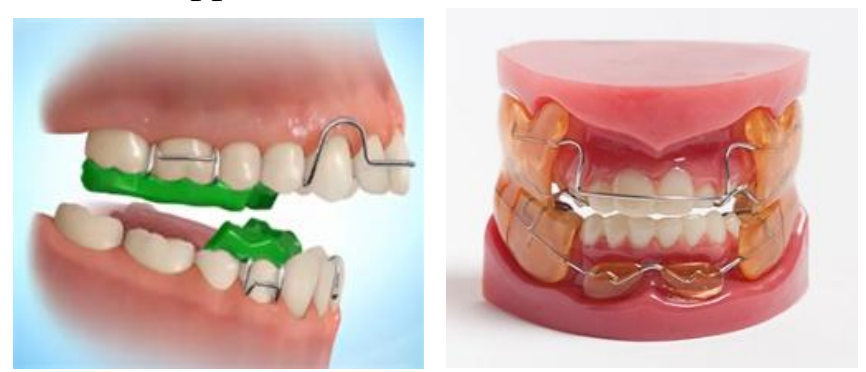

Fig.5-Myofunctional appliances for deep bite correction

\subsubsection{Headgears}

Cervical headgears exert a vertically downward component of force of about 200-300 g per side for duration of 14-16 $\mathrm{h}$ per day .This creates potential for extrusion of the molars and the deepbite get corrected. $^{(26)}$

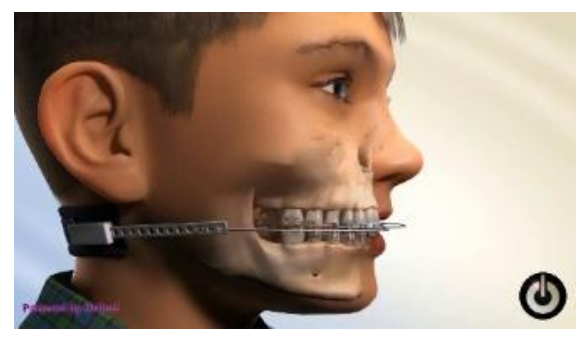

Fig.6-Cervical headgear

\subsection{Intrusion of Anterior Teeth}

For intrusion of teeth the force should pass through centre of resistance so as to translate teeth without tipping. Any force away from centre of resistance may cause flaring of incisors. Many researchers such as Reitan, Burstone, Bench, Gugino and Hilgers, Rickett, Liu and Herschleb, Kesling, Proffit, Karanth and Shetty have suggested various 
optimal intrusive forces. However an unanimous decision is lacking. Average force varies from 15-20 $\mathrm{g}$ for each upper incisor and 10-15 $\mathrm{g}$ for each lower incisor is recommended. In adults, the forces are to be applied carefully and somewhat towards a lower range ${ }^{(27)}$

\subsubsection{Beggs technique}

Bite opening bends are given so as to intrude the upper and lower anterior teeth so as to correct anterior deep bites ${ }^{(28)}$.Use of continous archwire for opening the bite, can have undiserable effects on anchorage the units ${ }^{(29)}$ Therefore use of Auxillary archwire such as utility arch, Burstone's 3 piece intrusion $\operatorname{arch}^{(30)(31)}$ Mulligan's intrusive $\operatorname{arch}^{(32)} \mathrm{K}$ SIR arch ${ }^{(33)}$ and $\mathrm{CIA}^{(34)}$ can be usd along with preadjusted edgewise technique to bring about intrusion of the anterior teeth without taxing the anchorage units.

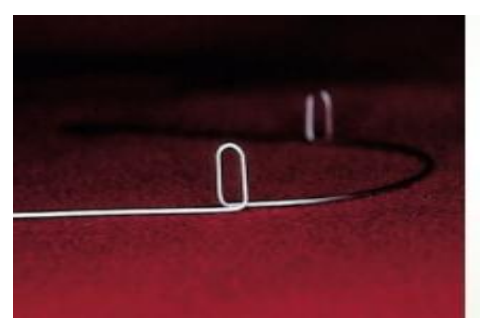

Fig.7-K-sir Loop

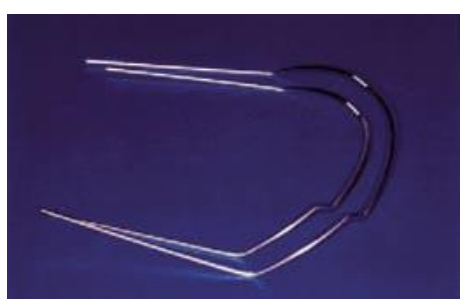

Fig.8-Connecticut Intrusion Arch

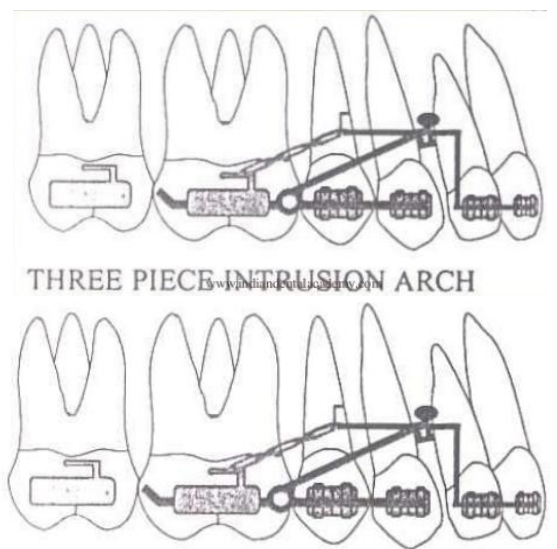

THREE PIECEWAMARUSHON ARCH

Fig.9-Burstones 3 piece intrusion arch
3.2.2 Correction of Deep Bite with Lingual Orthodontic

The distance in the sagittal plane between a lingual bracket and the $\mathrm{Cr}$ is much shorter than between a buccal bracket ${ }^{(35)}$ and the $\mathrm{Cr}$. Therefore, intrusion movement by lingual orthodontic will be closer to bodily movement and would be easy to achieve.

\subsection{Combination of Intrusion and Extrusion}

By altering positioning of brackets i.e.by placing anterior brackets occlusally and posterior brackets gingivally, or by using reverse-curve archwires, simultaneous intrusion of anterior teeth and extrusion of posterior teeth can be achieved. However, there is absolute no control over such mechanics. $^{(35)}$

\subsection{Correction of Deep Bite with Mini-Implants As Anchorage System}

Mini-implants can (nanda) be effectively used for en masse intrusion of anterior teeth(36)Factors to consider when placing mini-implants for intrusion of anterior teeth include availability of sufficient interdental bone, less soft tissue irritation, and a larger anterior segment (if all six anterior teeth are included), which requires greater control. In the authors' experience the interdental bone between the roots of the canine and lateral incisors(bilaterally) is an appropriate location for placement of miniimplants. The placement of the mini-screws should be done after levelling and alignment, in order to maximize the interradicular space at the placement site. In order to avoid tipping the upper incisors buccally during the intrusion, the end of the arch wire is cinched back.

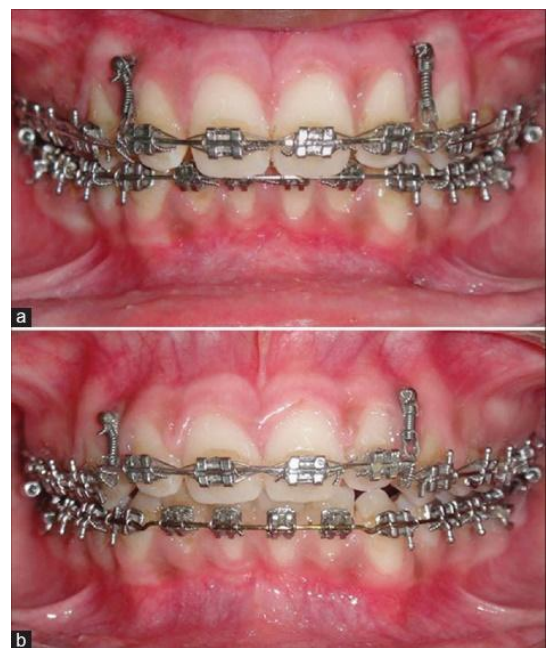

Fig.10-Implants for Intrusion 
3.5 Correction of Deep Bite with Orthodontics and Surgery

An adult who has more than $6 \mathrm{~mm}$ overbite could be considered a candidate for surgery solely on the basis of dental relationships, without even considering facial esthetics. ${ }^{(38)}$

\section{Retention and Stability}

Deepbite correction can be achieved by a variety of methods but maintenance of the correction is challenging. The results of most studies regarding the stability of overbite correction suggest a decrease in overbite during treatment, followed by an increase in the overbite after appliance removal, although clinically this might not be significant. ${ }^{(39)}$

\subsection{Factors to Consider when Planning Retention For Deep-Overbite Correction}
1. Age
2. Growth Pattern
3. Molar Extrusion/Incisor Intrusion,
4. And Interincisal Angle.

\subsubsection{Age}

Deep-bite correction is usually accomplished by simultaneous intrusion of incisors and extrusion of the posterior teeth. Growing patients benefit the most with this approach because active vertical growth during deep-bite correction ensures greater stability.

\subsection{Growth Pattern}

Hyperdivergent facial types usually exhibit a more favorable reaction to overbite correction than hypodivergent types.

\subsection{Molar Extrusion/Incisor Intrusion}

Molar extrusion in growing patients is a fairly stable procedure if the interocclusal space is not violated. Other factors that can lead to relapse of incisor intrusion are continued lower incisor eruption, occlusal canting, incomplete leveling of the curve of Spee and upward rotation of the mandible. $\mathrm{m} \mathrm{m}$

\subsection{Interincisal Angle}

Reidel $^{(40)}$ suggested that a large interincisal angle at the end of treatment is associated with relapse of deep overbite, possibly because a large interincisal angle tends to force the crowns of the mandibular incisors lingually and the apex of the maxillary incisors labially. Burzin and Nanda ${ }^{(39)}$ showed that the axial inclination of the incisors did not change significantly during a 2-year posttreatment observation period. And thus it can be a treatment a factor in overbite stability.

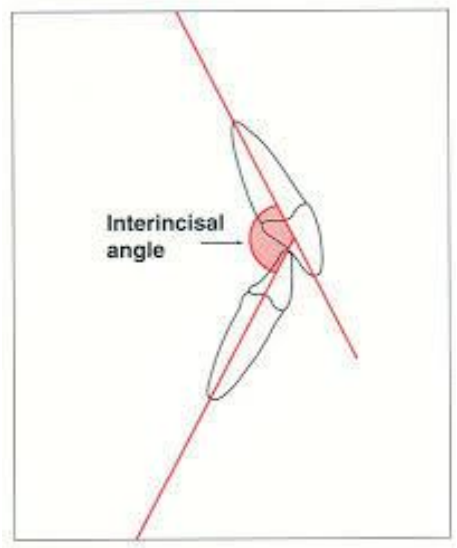

Fig.11-Interincisal Angle

\section{Summary and Conclusion}

Deep overbite is a common malocclusion in adults and children. The importance of accurate diagnosis, which entails detailed identification of the etiological factors cannot be overstressed because effective and efficient treatment of deep bite and long-term retention depend on it. Additionally, esthetic considerations including maxillary incisor to- lip relationship and the gingival exposure on smiling are also important diagnostic features that must be considered in the $b$ treatment plan.

\section{References}

1. Baratam S. Deep overbite-A review (Deep bite, Deep overbite, Excessive overbite). Ann essences Dent. 2009;1(1):8-25.

2. Strang RHW: A textbook of orthodontia, Philadelphia, 1950, Lea \&Febiger.

3. Parker CD, Nanda RS, Currier GF. Skeletal and dental changes associated with the treatment of deep bite malocclusion. Am J Orthod Dentofac Orthop. 1995;107(4):38293.

4. Upadhyay M, Nanda R. Etiology, Diagnosis, and Treatment of Deep Overbite. In: Nanda R, Kapila S. Current Therapy in Orthodontics (Mosby Elsevier; 2010. P 186198). 
5. Fleming HB. An investigation of the vertical overbite during the eruption of the permanent dentition. Angle Orthod1961;31: 53-62.

6. Prakash P, Margolis HI. Dento-craniofacial relations invarying degrees of overbite. Am J Orthod 1952;38:657-73.7.

7. Popovich F. Cephalometric evaluation of vertical overbite in young adults. J Canadian Dent Assoc 1955;21:209-22.

8. Goldstein MS, Stanton FL. Various types of occlusion and amounts of overbite in normal and abnormal occlusion between two and twelve years. Int $\mathbf{J}$ Orthod Oral Surg 1936;22:549-69.

9. Wylie WE The relationship between ramus height, dental height, and overbite. AM J ORTHOD ORAL SURG 1946;32:57-67.

10. Steadman SR. Predetermining the overbite and overjet. Angle Orthod 1947;19:101-5.

11. Neff CW. Tailored occlusion with the anterior coefficient. AM J ORTHOD ORAL SURG 1949;35:309-14.

12. Bresonis WL, Greive JM. Treatment and posttreatment changes in orthodontic cases: overbite and overjet. AngleOrthod 1974;44:295-9.

13. Nanda RS, Khan I, Anand R. Age changes in the occlusal pattern of deciduous dentition. J Dent Res 1973;52:221-4.

14. Bell W, Jacobs J, Legan H: Treatment of Class II deep bite by orthodontic and surgical means, Am J Orthod 85:1-19,1984.

15. Simons M, Joondeph D: Change in overbite: a ten-year postretention study, Am J Orthod 64:349-367, 1973.

16. Moyers RE: Handbook of orthodontics, ed 4, Chicago, 1988,Year Book Medical Publishers, pp 422-424.

17. Wehrbein H, Bauer W, Diedrich P: Mandibular incisors,alveolar bone, and symphysis after orthodontic treatment: a retrospective study, Am J Orthod Dentofacial Orthop 110:239-246, 1996.
18. Geiger A, Hirshfeld L (1974) Minor tooth movements in general practice (3rd edn.), Mosby Co.

19. Walther DP (1966) Current Orthodontics eight Teachers. In: Bristol (ed.) John Wright and Sons Ltd.

20. Jacksons, Sandler PJ (1996) Fixed bite planes for treatment of deep bite. J ClinOrthod 30: 283-287.

21. Philippe J (1996) Treatment of deep bite with bonded bite planes. J ClinOrthod 30: 396-400.

22. Graber TM, Neuman B (1984) Removable orthodontic appliances (2nd edn.), W.B. Saunders Co. Philadelphia, USA.

23. Graber TM, Rakosi T, Petrovic G (1985) Dentofacial Orthopedics with functional Appliances, St. Louis, Mosby Co.

24. Bhalaji SI (2015) Orthodontics: The art and science. Arya publishing house, New Delhi, India.

25. Clark WJ (1995) Twin block Functional therapy, application in dentofacial Orthopaedics. Mosby-Wolfe.

26. Toshniwal NG, Hazarey PV (1992) Extraoral orthodontic appliances. Library dissertation. Department of Orthodontics, G.D.C.H. Nagpur, India.

27. Divakar HS, Shetty S (2001) Comparative study of various intrusive arches. J IndOrthodSoc 34: 82-91.

28. Jayade VP (1997) Refined Begg's for Modern Times (1st edn.). In: Jayade AV (ed.) Hubli, India.

29. Bennett J, McLaughlin R (1990) Management of deep bite with a preadjusted appliance system. J ClinOrthod 24: 684-696.

30. Shroff B, Yoon WM, Lindauer SJ, Burstone CJ (1997) Simultaneous intrusion and retraction using a three piece base arch Angle. Orthod 67: 455-461.

31. Shroff B, Lindauer SJ, Burstone CJ (1995) Segmented approach to simultaneous intrusion and space closure. Am J Orthod 107: 136-143. 
32. Mulligan (1980) Common sense mechanics Part-12. J ClinOrthod 14: 546-553.

33. Kalra V (1998) Simultaneous intrusion and retraction of the Anterior teeth. J ClinOrthod 35: 535-540.

34. Nanda R, Marzban R, Kuhlberg A (1998) Theconnecticut Intrusion Arch. J ClinOrthod 35: 708-715.

35. Woods MG: The mechanics of lower incisor intrusion: experiments in non-growing baboons, Am J Orthod 93:186-195, 1988.

36. Melsen B, Fotish V, Burstone CJ: Vertical force considerations in differential space closure, J ClinOrthod 24:678-683, 1990.

37. Blechman AM (1985) Magnetic force systems in orthodontics. Am J Orthod 87: 201-210.

38. Proffit WR, White RP (1990) Surgical orthodontic treatment. Mosby Co.

39. Burzin J, Nanda R: The stability of deep overbite correction. In Nanda R, Burstone CJ, editors: Retention and stability in orthodontics, Philadelphia, 1993, Saunders, pp 61-79.

40. Riedel RA: A review of the retention problem, Angle Orthod 30:179-194,1960. 